\title{
Estimating little auk (Alle alle) breeding density and chick-feeding rate using video surveillance
}

\author{
Anders Mosbech ${ }^{a}$, Peter Lyngs ${ }^{a, b}$ \& Kasper Lambert Johansen ${ }^{a}$

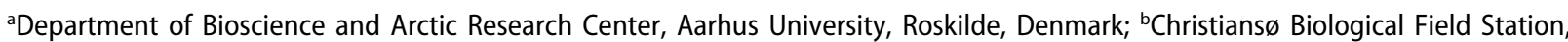 \\ Christiansø, Denmark
}

\begin{abstract}
High Arctic ecosystems are under change and need to be monitored. We studied little auks (Alle alle), the most abundant seabird in the North Atlantic, in their main breeding area in the North Water Polynya region of High-Arctic north-west Greenland. We developed a method for estimating breeding density and chick-feeding rate based on video surveillance. As the nests of little auks are secluded between rocks and cannot be directly observed, the method rests on detailed recording of feeding events, when parent birds arrive from the sea with filled gular pouches and disappear into the scree to feed their chicks, supplemented with recording of fledging and pre-fledging behaviour of chicks outside the nesting holes. We installed video cameras in two study plots during the late chick-rearing and fledging periods $2-11$ August 2012 and 5 - 12 August 2013, and the method proved useful for estimating the density of active nests immediately prior to fledging (which corresponds roughly to productivity of fledglings $/ \mathrm{m}^{2}$ ). The densities of active nests for the two plots in 2012 and 2013 ranged between 1.06 and 1.63 nests $/ \mathrm{m}^{2}$, and an average of $9.1 \mathrm{feeds} / \mathrm{chick} / \mathrm{day}(n=8$ pairs, $3 \times 24$ h, 219 feedings) was recorded for this late stage of the chick-rearing period. Our video surveillance method has advantages over the mark-resight methods and other techniques used to monitor little auk colonies.
\end{abstract}

\section{KEYWORDS}

Seabird colony monitoring methods; seabird ecology; north-west Greenland; North Water Polynya; High Arctic

\section{ABBREVIATIONS}

WGST: Western Greenland Summer Time; SD: secure digital

\section{Introduction}

Climate will change faster in the Arctic than further south and monitoring population trends for key species is pivotal for protecting biodiversity, understanding ecosystem change and taking adaptation actions (Arctic Council Expert Group on Ecosystem-Based Management 2013; Meltofte 2013; Irons et al. 2015). The little auk (Alle alle) is the most abundant seabird in the North Atlantic (Barrett et al. 2006). It breeds in extensive colonies in the High Arctic, laying a single egg in cavities in scree on steep mountain slopes (Stempniewicz 2001). The little auk will be exposed to climate-driven changes in the marine environment, but the potential to adapt via a range shift of breeding colonies towards the north into the Arctic Ocean is limited. The threat of climate change to little auks has therefore received scientific attention with primary focus on the linkages with the High-Arctic marine food web during the breeding season (Karnovsky et al. 2011; Grémillet et al. 2015). Northern oil activities, expansion of shipping routes and long-distance, atmospherically transported contaminants have been suggested as other potential threats (Fort et al. 2013) and monitoring little auk population trends has been recommended (Irons et al. 2015).
However, as little auk nests are secluded between rocks, assessment of breeding density is not straightforward. Estimates have been produced by attempts to count nests directly (Evans 1981; Stempniewicz 1981) or by calculating nest density based on the proportion of resightings of a known number of marked birds in a study plot, followed by comparisons with the number of unmarked birds observed in the plot (mark-resight model; e.g., Isaksen \& Bakken 1995; Kampp et al. 2000). As most nests in our study area in north-west Greenland were located deep in the scree, a direct count of nests by checking holes with an arm or a tube inspection camera was not possible. The markresight model was also unsuitable in our case because of an unknown proportion of non-breeders (e.g., Kampp et al. 2000) and, especially, because of the presence of an unknown and variable number of visitors from other parts of the breeding colony in our study plot at any given time. This violates the assumption of the mark-resight method that birds observed in the study plot are actually breeding in the plot or form part of a known fraction of non-breeders.

We developed an alternative method based on video surveillance of study plots during the late chick-rearing and fledging periods, which allows us to estimate the density of occupied nests immediately prior to fledging. As little auks raise only a single chick, this figure

CONTACT Anders Mosbech amo@bios.au.dk EDepartment of Bioscience, Aarhus University, Frederiksborgvej 399,4000 Roskilde, Denmark 
corresponds closely to the productivity of fledglings per area unit. The estimate is based on detailed recording of feeding events, when parent birds arrive from the sea with filled gular pouches and disappear into the scree to feed the chicks. The choice of study period allowed us to supplement these data with recording of fledging events and associated pre-fledging behaviour of chicks outside the nesting holes. As an integrated part of the method, chick-feeding rates are also obtained, and these potentially constitute another important monitoring parameter.

\section{Material and methods}

We studied little auks in their main breeding area in north-west Greenland, where an estimated 33 million pairs, or $80 \%$ of the global little auk population, breed in colonies distributed within a range of $325 \mathrm{~km}$ along the eastern shores of the North Water Polynya (Boertmann \& Mosbech 1998; Egevang et al. 2003). The study was conducted within a large colony in the valley of Qoororsuaq $\left(76^{\circ} 16^{\prime} \mathrm{N}, 68^{\circ} 58^{\prime} \mathrm{W}\right), 21 \mathrm{~km}$ south-east of Cape Atholl and $3 \mathrm{~km}$ north-west of the Pituffik Glacier (Fig. 1). We selected two study plots ( $\mathrm{Mv}$ and $\mathrm{Vv}$ ) within the western part of the colony on the north slope of the valley. Both plots were positioned in boulder scree with large stones (average diameter $30-40 \mathrm{~cm}$ ). The $\mathrm{Mv}$ plot was placed in what we deemed to be a high-density area and the Vv plot in a semi-high- density area-as opposed to lower density areas on the outskirts of the colony. The boundaries of the plots were marked with dots of red paint. Following the mountain slope, the surface area of the Mv plot was $6.75 \mathrm{~m}^{2}$ and that of the $\mathrm{Vv}$ plot $4.71 \mathrm{~m}^{2}$. At each plot, we installed a JVC Everio GZ dual slot camcorder (in 2012 the HM200, in 2013 the EX515), each equipped with two SD memory cards. The video cameras were placed on tripods and protected against the weather by Ewa Marine rain covers. At plot $\mathrm{Vv}$, the video camera was placed above the plot and $3 \mathrm{~m}$ uphill from the plot border. At plot Mv, the video camera was situated at the same level as the plot, $4.6 \mathrm{~m}$ from the plot border. The video cameras operated in XP-mode (17 Mbps, VBR $1920 \times 1080$, two-channel digital Dolby sound) and were powered by external batteries (Vision 6FM $12 \mathrm{v} 7.2 \mathrm{Ah}$ ). We charged the batteries in camp, replacing them and the SD cards on a daily basis.

Both video cameras recorded during late chickrearing and fledging in the periods 2 - 11 August 2012 and 5 - 12 August 2013, capturing a total of $344 \mathrm{~h}$ and two minutes of video footage. As feeding and fledging activity in the colony primarily took place between 24:00 and 10:00 WGST, the video cameras were usually started around midnight and continued recording until the SD cards ran full 8 - 10 h later. However, during 8 - 10 August 2013, the video camera at plot $\mathrm{Mv}$ ran continuously for $24 \mathrm{~h} /$ day to obtain the full diurnal activity pattern.

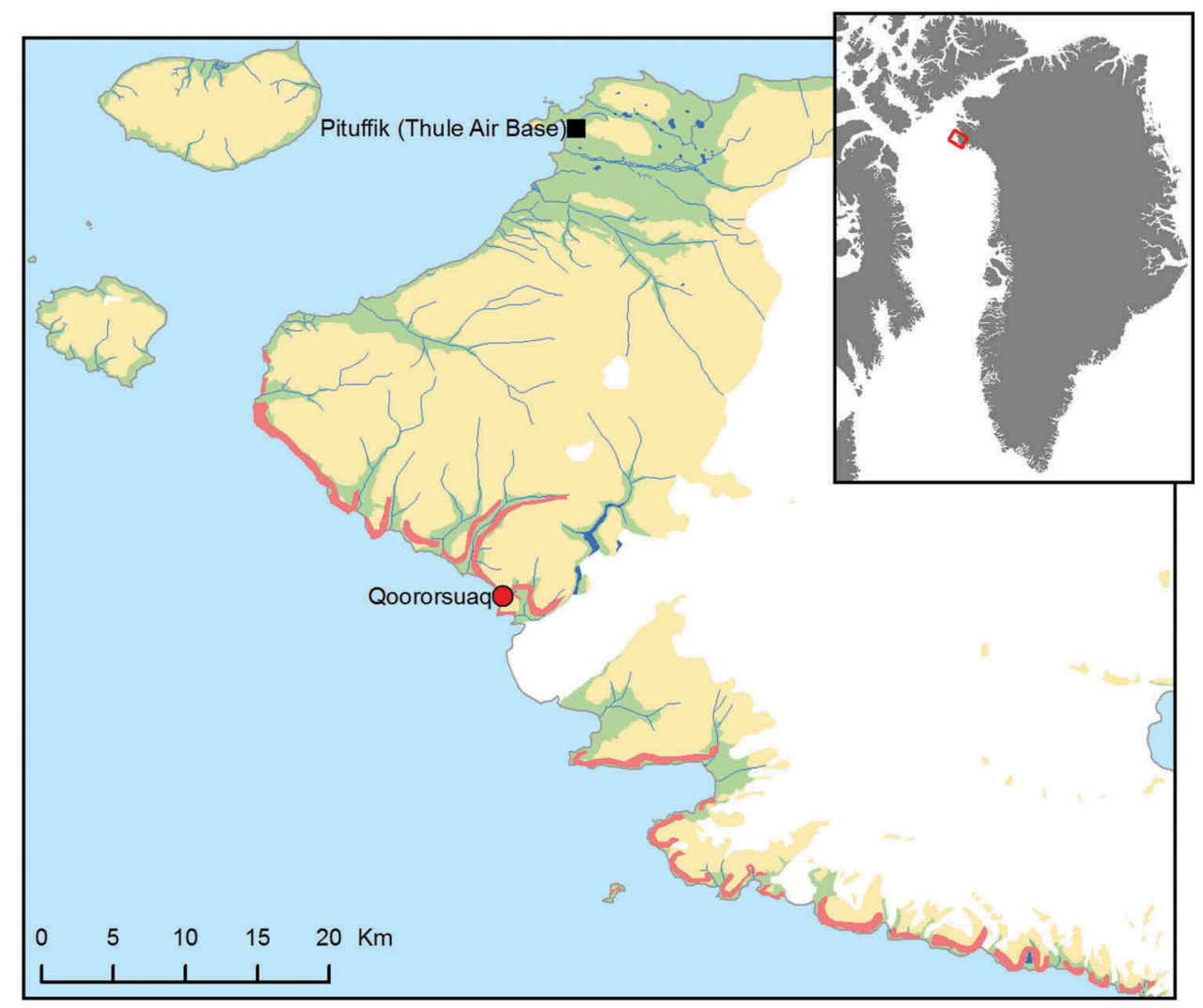

Figure 1. Map of the study area and location of the study site (red dot). The distribution of little auk colonies is shown in pale red (after Boertmann \& Mosbech 1998). Basemap reproduced with permission from Danish Geodata Agency. 
In previous years, six of the birds breeding in the $\mathrm{Mv}$ plot had been ringed with a metal ring and/or colour rings and on 5-6 August 2013 we individually marked a further five birds (three males, two females) from three pairs (nests 6, 8 and 9) in this plot using picric acid. All marked birds were sexed by analysing DNA from feather samples (see "molecular sexing" in Frederiksen et al. 2014). In the Vv plot, all birds were unmarked.

Food-carrying adults, returning from sea to feed the chick, are easily identifiable, as they carry the food in a bulging gular pouch. They always land some distance away from their nest, often in groups consisting of several food-carrying birds from the same area. They then approach their nest entrance in a series of short flights or jumps (average duration of approach $43 \mathrm{~s}$, range $2 \mathrm{~s}-2: 50 \mathrm{~min}, n=84$ ), and disappear into a nesting hole to feed the chick. When undisturbed, they reappear with an empty gular pouch after a few minutes (average duration in nest 3:34 min, range 1:01 - 8:31 $\mathrm{min}, n=50)$. Observations of marked birds revealed that some birds used several entrances/exits to the nest, and that different pairs in some cases used the same surface entrances. However, observations of marked birds also revealed that each bird tended to use distinct routes of approach (Fig. 2). This makes individual recognition of unmarked birds possible and helps resolve matters in cases of multiple/overlapping entrances. In the days prior to fledging, the chicks start to appear outside the nesting hole for short periods, occasionally conducting a characteristic wing-flapping and interacting with a parent. The chicks are distinguishable from adult birds and often distinguishable from each other (e.g., based on different throat-feather patterns). This pre-fledging behaviour of chicks, and the actual fledging event, form supplementary cues to establishing the presence of active nests.

Estimating the number of active little auk nests on the basis of the video footage can be described as a process of pattern finding, gradually piecing together these different bits of information. All video footage was watched on a computer by the same observer (PL) using VCL Media Player or Daum PotPlayer with the sound turned on, making extensive use of the possibility to speed up when nothing happened $(\times 2-4)$, and to stop, rewind and re-play in slow motion when a significant event took place. Each food-carrying little auk landing in or just outside the plot was followed until it entered a nesting hole and often recorded again when exiting the nest. For each such feeding event, route of approach, identity of the bird (if possible), and time and position of entry and exit were recorded. The entrance/exit holes were numbered and mapped on a still frame from each plot (Fig. 3). Time and position of sightings of chicks (fledging or engaged in pre-fledging behaviour), including their use of nesting holes, were also recorded. By overlaying all this information, the number of active nests in each plot could be determined.

\section{Results and discussion}

The video surveillance proved to be a useful method to estimate the density of active nests. In 2012, 17 active nests were determined based on feeding events (adult entrances) and 17 individual large $(20 \mathrm{~d}+)$ chicks were recorded. Of these chicks, actual fledging of 10 was recorded, four were still in the nest when the study terminated and three disappeared (fledged

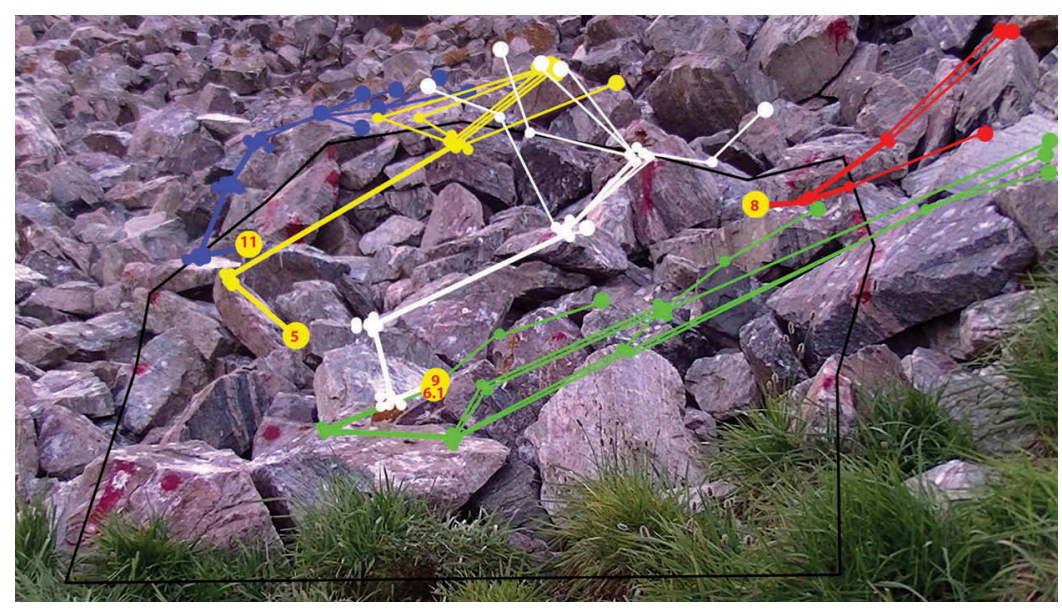

Figure 2. An example of approach routes to the nest of five food-carrying little auks from plot Mv, Qoororsuaq, north-west Greenland, during a 24-h video recording on 9 August 2013. Plot border shown in black. Positions of nests are shown with large yellow dots including nest numbers; otherwise, larger unnumbered dots show landing place, smaller dots positions where the bird stopped briefly en route to the nest. The birds from nest 9 and nest 6.1 often used the same entrance. The figure is based on 27 feedings in total: seven feedings at nest 11 (blue), six at nest 9 (white), three at nest 8 (red), five at nest 6.1 (green) and six at nest 5 (yellow). 


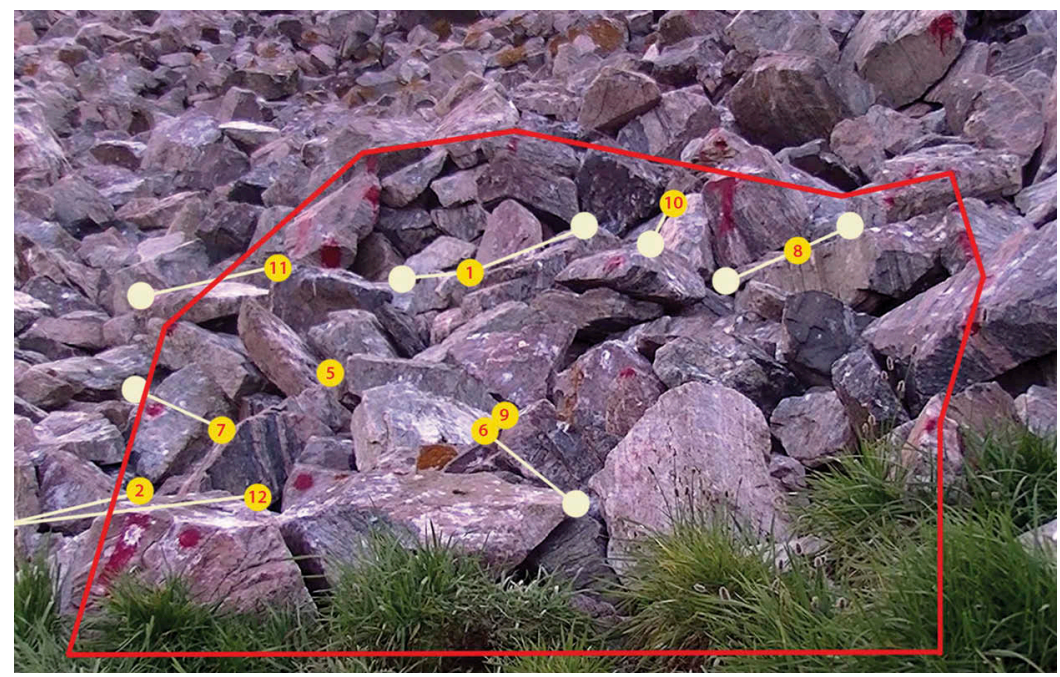

Figure 3. Video still frame of plot Mv, 2013. The active nest holes (yellow dots) and the different supplementary entrance/exit holes (light yellow dots) used are linked with light yellow lines. The birds from nests 2 and 12 and from nests 6 and 9 often used the same entrance.

or died) during the daytime on 10 August when the video camera was not on. In 2013, 15 active nests were identified and 10 large chicks were recorded. The breeding season of 2013 occurred three days later than in 2012 and the actual fledging of only one chick was recorded, the remaining chicks still being in the nest when the study was terminated.

The resulting densities of active nests for the two plots in 2012 and 2013 ranged between 1.63 nests $/ \mathrm{m}^{2}$ (11 active nests Mv plot 2012) and 1.06 nests $/ \mathrm{m}^{2}$ (five active nests Vv plot 2013; see Table 1). These densities should be regarded as a minimum estimate of breeding density as the study took place at the very end of the breeding period and does not provide information on failed breeding attempts earlier in the season. Given the timing of the study, the nest densities found should correspond closely to the productivity of fledglings per $\mathrm{m}^{2}$. The high breeding densities found in this study cannot be directly extrapolated to all the little auk colonies mapped in the Thule area, which are distributed across a range of $325 \mathrm{~km}$, have different scree morphology and therefore probably different little auk breeding densities. A detailed mapping of colony geomorphology along with a substantial number of density plots will be needed to produce an estimate that is appropriate for the whole Thule area.

Table 1. The number and density of active little auk nests at the end of the breeding season in the two study plots at Qoororsuaq, north-west Greenland, 2012-13. The nest density corresponds closely to the productivity of fledglings per square metre.

\begin{tabular}{lccccc}
\hline & \multicolumn{2}{c}{ Mv plot } & & \multicolumn{2}{c}{ Vv plot } \\
\cline { 2 - 4 } \cline { 5 - 6 } Year & Nest $(n)$ & Nest $/ \mathrm{m}^{2}$ & & Nest $(n)$ & Nest $/ \mathrm{m}^{2}$ \\
\hline 2012 & 11 & 1.63 & 6 & 1.27 \\
2013 & 10 & 1.48 & 5 & 1.06 \\
Mean & & 1.56 & & 1.17 \\
\hline
\end{tabular}

Analysing the video footage was time-consuming (ca. $40 \mathrm{~min}$ viewing/ $\mathrm{h}$ footage). The main difficulty arose from the fact that many birds used more than one entrance to the nest or, in a few cases, that two pairs used the same surface entrance (Mv plot 2013). For example, in the Mv plot in 2013, holding 10 pairs, $60 \%$ of the nests had two or three entrances, and $70 \%$ had two or three exits. Assuming that every entrance used by a chick-feeding adult represented an active nest would have yielded an overestimation of the true number of active nests by $70 \%$. To reduce the time consumption of footage analysis, the video camera should have a good viewing angle, preferably from uphill down on the study plot, and as many birds as possible should be individually marked with picric acid. The emergence of chicks from the nests about 1 - 3 days before fledging can confirm the presence of active nests. It is therefore important that the video surveillance includes the pre-fledging period.

In addition to nest density, the analysis of feeding events during three days of continuous video recording in 2013 provided detailed information on the diurnal pattern of chick feeding and chick-feeding rates (Fig. 4). On average, we found 9.1 feedings/ chick/day ( $n=8$ pairs, $3 \times 24$ h, 219 feedings) during this late stage of the chick-rearing period, when females have reduced their feeding rate (Fig. 5) before the chick fledges and leaves the colony with the male parent (Stempniewicz 2001). Still, our feeding rate corresponds well with feeding rates published for breeding colonies around the Greenland Sea, which range from 7.4 to 9.7 feedings/chick/day (Welcker, Harding et al. 2009). Information on chick-feeding rates, likely reflecting marine feeding opportunities, can be a valuable monitoring parameter for little auk colonies, especially combined with the use of chick 


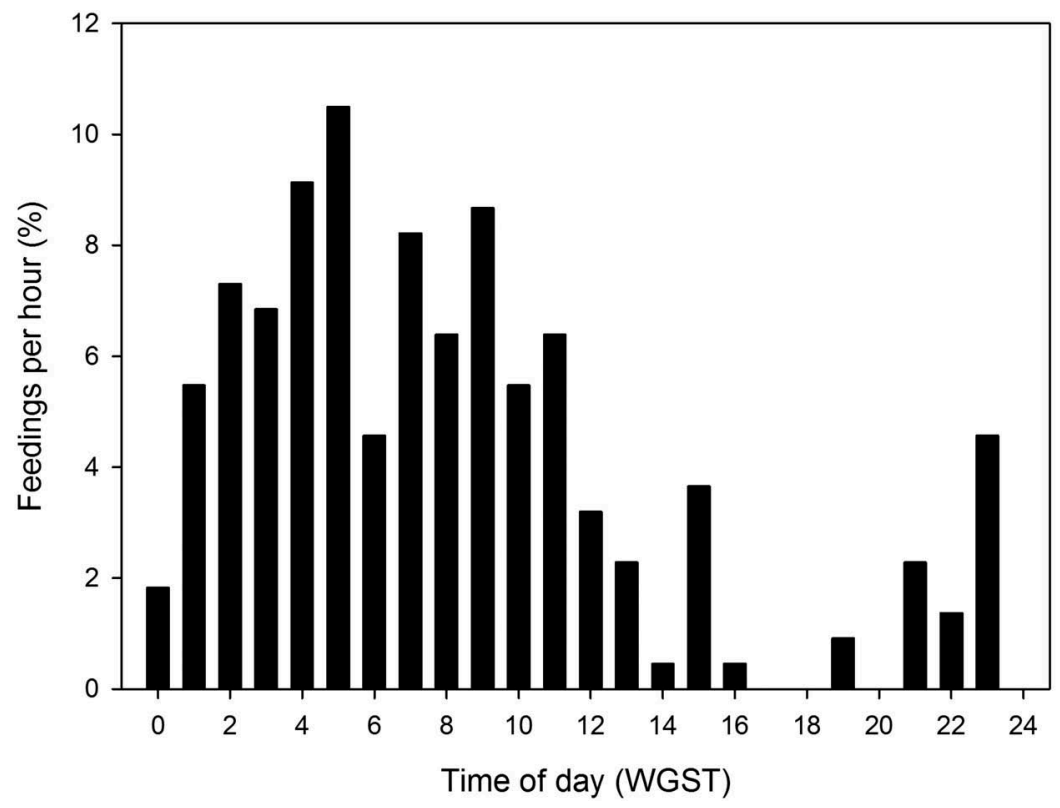

Figure 4. The diurnal feeding pattern in plot Mv during the late chick-rearing period, $8-10$ August 2013 (eight pairs, $3 \times 24 \mathrm{~h}$, 219 feedings).

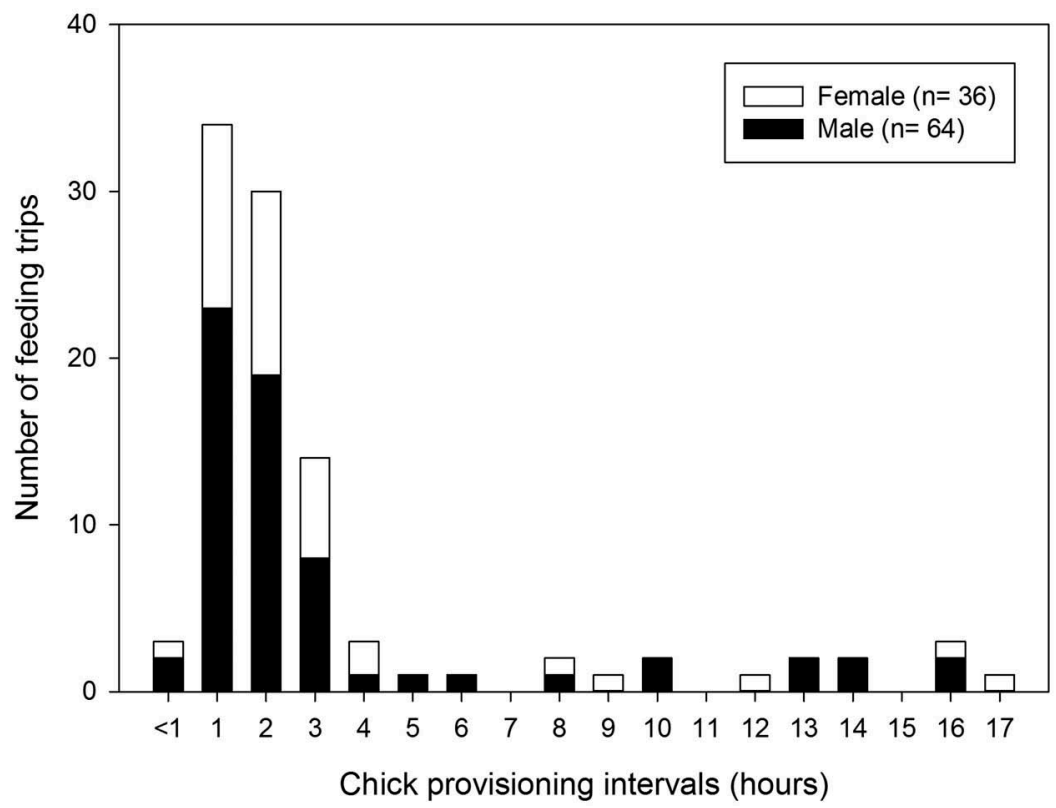

Figure 5. The frequency distribution of feeding intervals of sexed adults (three pairs) during the late chick-rearing period ( 8 - 10 August 2013, $3 \times 24 \mathrm{~h})$ in plot Mv $(n=100)$.

meals as (selective) samples of pelagic zooplankton (Welcker, Harding et al. 2009; Welcker, Steen et al. 2009; Frandsen et al. 2014). Chick-feeding rates of little auks have often been established by means of direct, 24-h observations of study plots with individually marked birds in the field or by analysing data from temperature, time-depth or GPS loggers deployed on breeding adults. While the former method may be prone to observer fatigue and missing observations, the latter approach has recently been criticized for yielding biased results as the birds may be affected by the burden of the logger (Kidawa et al. 2012). Our video surveillance method does not suffer from these shortcomings and may be a more suitable alternative monitoring technique.

The breeding density estimates from Qoororsuaq (Table 2) correspond well with the density estimates obtained from Gulliksenfjellet, Svalbard, using the mark-resight methodology (Isaksen \& Bakken 1995). Somewhat lower densities have been found with the mark-resight methodology in four other localities in north-west and north-east Greenland and Svalbard (Table 2).

The reason we abandoned the mark-resight methodology in Qoororsuaq was that breeding birds (birds with brood patch/filled gular pouch) marked in a 
Table 2. Overview of published nest density estimates from little auk colonies.

\begin{tabular}{|c|c|c|c|c|c|c|}
\hline Locality & $\begin{array}{l}\text { Density } \\
\text { (nest/m²) }\end{array}$ & Range & Breeding stage & $\begin{array}{l}\text { Boulder } \\
\text { diameter }\end{array}$ & Method & Authors \\
\hline Qoororsuaq, NW Greenland & 1.37 & $1.06-1.63$ & Late chick-rearing & $30-40 \mathrm{~cm}$ & $\begin{array}{l}\text { Videocam: feeding } \\
\text { events }\end{array}$ & This study \\
\hline Hakluyt, NW Greenland & 0.73 & $0.5-1.3$ & $\begin{array}{l}\text { Early-late chick- } \\
\text { rearing }\end{array}$ & $?$ & Mark-resight & Kampp et al. (2000) \\
\hline Horsehead, NW Greenland & 0.25 & NA & $?$ & $?$ & Nest count & Evans (1981) \\
\hline Kap Høegh, NE Greenland & 0.7 & NA & NA & $?$ & Mark-resight & Kampp et al. (1987) \\
\hline Gulliksenfjellet, Svalbard & 1.5 & $1.2-1.9$ & Early chick-rearing & $32-43 \mathrm{~cm}$ & Mark-resight & Isaksen \& Bakken (1995) \\
\hline Bjørndalen, Svalbard & 0.5 & $0.2-0.5$ & Incubation & $25 \mathrm{~cm}$ & Mark-resight & Isaksen \& Bakken (1995) \\
\hline Ariekammen, Svalbard & 0.6 & $0.5-0.7$ & $?$ & $?$ & Nest count & Stempniewicz (1981) \\
\hline
\end{tabular}

study plot were observed on rocks far from the plot, violating the assumption of the mark-resight model. Seabird behaviour can differ between colonies (e.g., Jakubas \& Wojczulanis-Jakubas 2011) and we have no reason to believe that the mark-resight estimates given for the other localities in Table 2 are biased. Where applicable, the two methods could be supplementary. Direct nest counts have been used for estimating nest density in two studies (Table 2), but the reliability of this method is challenged by the location of many of the nests deep below the stones.

\section{Conclusion}

Establishing integrated ecosystem monitoring programmes to support adaptive management is needed in the rapidly changing High-Arctic environment and is recommended by Arctic Council working groups such as Conservation of Arctic Flora and Fauna and Protection of the Arctic Marine Environment. In this context, the video surveillance method presented here can be a valuable element in monitoring little auk colonies, especially as the technological development of video cameras leads to improvements of storage, battery capacity and optical resolution. A monitoring programme combining this method with analysis of little auk chick meals (zooplankton "samples") and studies using time-depth and GPS loggers on foraging birds will allow assessment of how successfully little auks adapt foraging behaviour to a High-Arctic environment under change (see, e.g., Jakubas et al. 2016).

\section{Acknowledgements}

We want to acknowledge the base commander at Thule Air Base for permission to use the base, and the Danish Liaison Officer and Greenland Contractors, especially Tony Rønne Pedersen, Hans Otzen and Erland Søndergård, for extensive logistic and practical help. Molecular sexing was carried out by Liselotte Wesley Andersen. Flemming Merkel is acknowledged for assistance with video camera set-up and David Boertmann, Nicholas P. Huffeldt and Allan J. Kristensen for assistance in the field. Two anonymous reviewers provided useful comments.

\section{Disclosure statement}

No potential conflict of interest was reported by the authors.

\section{Funding}

The fieldwork was undertaken as part of the Baffin Bay Environmental Study Program 2011-14 conducted by the Danish Centre for Environment and Energy, Aarhus University, and the Greenland Institute of Natural Resources funded by the Bureau of Minerals and Petroleum, Greenland Government. The North Water Project funded by the Velux Foundations and the Carlsberg Foundation covered part of the analytical and writing costs.

\section{References}

Arctic Council Expert Group on Ecosystem-Based Management 2013. Ecosystem-based management in the Arctic. Tromsø: Arctic Council.

Barrett R.T., Chapdelaine G., Anker-Nilssen T., Mosbech A., Montevecchi W.A., Reid J.B. \& Veit R.R. 2006. Seabird numbers and prey consumption in the North Atlantic. ICES Journal of Marine Science 63, 1145-1158.

Boertmann D. \& Mosbech A. 1998. Distribution of little auk (Alle alle) breeding colonies in Thule District, northwest Greenland. Polar Biology 19, 206-210.

Egevang C., Boertmann D., Mosbech A. \& Tamstorf M.P. 2003. Estimating colony area and population size of little auks Alle alle at Northumberland Island using aerial images. Polar Biology 26, 8-13.

Evans P.G.H. 1981. Ecology and behaviour of the little auk Alle alle in west Greenland. Ibis 123, 1-18.

Fort J., Moe B., Strøm H., Grémillet D., Welcker J., Schultner J., Jerstad K., Johansen K., Phillips R.A. \& Mosbech A. 2013. Multicolony tracking reveals potential threats to little auks wintering in the North Atlantic from marine pollution and shrinking sea ice cover. Diversity and Distributions 19, 1322-1332.

Frandsen M.S., Fort J., Rigét F.F., Galatius A. \& Mosbech A. 2014. Composition of chick meals from one of the main little auk (Alle alle) breeding colonies in northwest Greenland. Polar Biology 37, 1055-1060.

Frederiksen M., Falk K., Huffeldt N.P., Johansen K., Labansen A.L., Linnebjerg J.F., Merkel F. \& Mosbech A. 2014. Seabird baseline studies in Baffin Bay 2008-2013. Colony-based fieldwork at Kippaku and Apparsuit, NW Greenland. Scientific report from DCE - Danish Centre for Environment and Energy 110. Aarhus: Aarhus University, Danish Centre for Environment and Energy. 
Grémillet D., Fort J., Amélineau F., Zakharova E., Le Bot T., Sala E. \& Gavrilo M. 2015. Arctic warming: nonlinear impacts of sea-ice and glacier melt on seabird foraging. Global Change Biology 21, 1116-1123.

Irons D., Petersen A., Anker-Nilssen T., Artukhin Y., Barrettt R., Boertmann D., Gavrilo M.V., Gilchrist G., Hansen E.S., Hario M., Kuletz K., Mallory M., Merkel F., Mosbech A., Labansen A.L., Olsen B., Österblom H., Reid J., Robertson G., Rönkä M. \& Strøm H. 2015. Circumpolar seabird monitoring plan. CAFF Monitoring Report 17. Akureyri: Conservation of Arctic Flora and Fauna International Secretariat.

Isaksen K. \& Bakken V. 1995. Estimation of the breeding density of little auks (Alle alle). In K. Isaksen \& V. Bakken (eds.): Seabird populations in the northern Barents Sea. Source data for the impact assessment of the effects of oil drilling activity. Norsk Polarinstitutt Meddelelser 135. Pp. 37-47. Tromsø: Norwegian Polar Institute.

Jakubas D. \& Wojczulanis-Jakubas K. 2011. Subcolony variation in phenology and breeding parameters in little auk Alle alle. Polar Biology 34, 31-39.

Jakubas D., Wojczulanis-Jakubas K., Boehnke R., Kidawa D., Błachowiak-Samołyk K. \& Stempniewicz L. 2016. Intra-seasonal variation in zooplankton availability, chick diet and breeding performance of a High Arctic planktivorous seabird. Polar Biology 39, 1547-1561.

Kampp K., Falk K. \& Egevang Pedersen C. 2000. Breeding density and population of little auks (Alle alle) in a northwest Greenland colony. Polar Biology 23, 517-521.
Kampp K., Meltofte H. \& Mortensen C.E. 1987. Population size of the little auk Alle alle in east Greenland. Dansk Ornitologisk Forenings Tidsskrift 81, 129-136.

Karnovsky N., Brown Z., Welcker J., Harding A., Walkusz W., Cavalcanti A., Hardin J., Kitaysky A., Gabrielsen G. \& Grémillet D. 2011. Inter-colony comparison of diving behavior of an Arctic top predator: implications for warming in the Greenland Sea. Marine Ecology Progress Series 440, 229-240.

Kidawa D., Jakubas D., Wojczulanis-Jakubas K., Iliszko L. \& Stempniewicz L. 2012. The effects of loggers on the foraging effort and chick-rearing ability of parent little auks. Polar Biology 35, 909-917.

Meltofte H. (ed.) 2013. Arctic biodiversity assessment. Status and trends in Arctic biodiversity. Akureyri: Conservation of Arctic Flora and Fauna International Secretariat.

Stempniewicz L. 1981. Breeding biology of the little auk, Plautus alle in the Hornsund region, SW Spitsbergen. Acta Ornithologica 18, 141-165.

Stempniewicz L. 2001. Little auk (Alle alle). In M. Ogilvie (ed.): BWP update. Vol. 3. The journal of the birds of the western Palearctic. Pp. 175-201. Oxford: Oxford University Press.

Welcker J., Harding A.M.A., Karnovsky N.J., Steen H., Strøm H. \& Gabrielsen G.W. 2009. Flexibility in the bimodal foraging strategy of a High Arctic alcid, the little auk Alle alle. Journal of Avian Biology 40, 388-399.

Welcker J., Steen H., Harding A.M.A. \& Gabrielsen G.W. 2009. Sex-specific provisioning behaviour in a monomorphic seabird with a bimodal foraging strategy. Ibis 151, 502-513. 